NASZA DERMATOLOGIA Online OUR DERMATOLOGY Online

Source of Support: Nil

Competing Interests: None

\section{SEYLE'S BIOLOGICAL STRESSORS INFLUENCE DRAMATICALLY SKIN PHYSIOLOGY: OUR EXPERIENCES WITH ELECTRICAL ADMITTANCE MAGNITUDE MEASUREMENTS}

\author{
Lorenzo Martini ${ }^{1}$, Roberto Solimé ${ }^{2}$ \\ ${ }^{1}$ University of Siena, Department of Pharmaceutical Biotechnologies, Via A.Moro 2, \\ 53100 Siena, Italy \\ ${ }^{2}$ Solimé s.r.l, Via Dalla Chiesa 10, Cavriago, Italy
}

Corresponding author: Lorenzo Martini, M.Sc.

lorenzo.martini@unisi.it

\begin{abstract}
Introduction: Abrupt changes of environmental temperatures and assault of chemical and physical assaults belong to the series of biological stresses recorded by the austro-canadian endocrinologist Seyle onto skin, phenomena that are progressively overset all natural events and anthropological lifestyles, are too often depreciated and underestimated by dermatologists and cosmetologists at all.

Aims of our study is to evaluate by electrical admittance magnitude measurements the influence these two irrefutable afflictions, designed as stressors, influence negatively human skin and to do this we have selected, to conduct the study, peculiar individuals that, owing to their choice of living, may or not be injured by extreme changes of temperatures and aggressions by chemical and physical pollutants.

Materials and Methods: We have recruited 20 nuns in a cloistered convent in Mid Italy: ten of these have been always accustomed to live inside the cloister and their life-style permits the good conservation of the intact skin physiology (that is living at air temperature and mediumlow relative humidity) and the other ten are accustomed to live and work outdoor and to be assaulted by abrupt and extreme changes of environmental temperature and pollutants. Cloistered nuns have the chance to choose where to live, indoor or aoutdoor. We measured the electrical admittance magnitude (in $\mu \mathrm{mho}$ ) at the beginning and at the end of the experiment that lasts 29 weeks, using an appropriate instrument based on the system developed by Feldman, working at a single frequency of $30 \mathrm{kHz}$.

Results and Conclusion: It is self evident that after the simulation of phyto-induced cortisol release onto the skins of all the 20 volunteers, the subjects that which live outdoor show an exaggerated value of dehydration with regard to the subjects that live indoor. Changes of environmental temperatures and chemical pollutants, is self evident, jeopardize human skin integrity and safety, but we have disclosed the eventuality that these phenomena may reveal devastative effects onto skin to drive even to a praecox skin senescence and degradation.
\end{abstract}

Key words: Water loss insensible; Global Warming; Xanthines

Martini L, Solimé R. Seyle's biological stressors influence dramatically skin physiology: our experiences with electrical admittance magnitude measurements. Our Dermatol Online. 2014; 5(2): 144-147.

\section{Introduction}

J.H.B. Selye $[1,2]$ recognized the role glucocorticoids, mineralcorticoids, sexual corticoids and cathecolamines play in the phenomenon of the biological stress and of the adaptation general syndrome, in other words he was aware of the hormonal response to stress in human.

According to the Author, there are four types of stresses: physical (e.g. inadequate sleep or rest, inadequate work/exercise, repetitive or asymmetrical movement at work/play, -physical injuries,-excessive or imbalanced work/exercise) chemical, (e.g. air and/or water pollution, pesticides and herbicides, solvents, industrial chemicals, flavourings, colourings, and preservatives, refined foods like hydrogenated oils, white flour, sugar, antibiotics and manifold medicines, dental amalgam, thermal, (e.g. extreme or prolonged heat or cold, extreme changes in temperature) and emotional (e.g. poor relationships and financial burdens, past emotional trauma, self-judgments like self-expectations of perfection, anticipation of harm, pain, or dreaded events).

Cortisol is the hormone most profoundly influenced by whichever of the aforesaid stresses, and in effect it has been very recently demonstrated that in case of mirthful laughters its level decreases deeply [3]. 
Actually, under stress, cortisol levels can run very high. Abnormal circadian rhythm normally will not develop until stress is prolonged - usually over years - but it can also occur in just a few months, especially if it is severe and constant.

When the cortisol rhythm stays out of balance [4], more serious problems can appear, such as arthritis, allergies, asthma, colitis, ulcers, recurrent and prolonged infections, autoimmune diseases, degeneration of the nervous system, and, we have supposed and argued, premature skin senescence and degradation, and this shall be the exact prolegomenon of our study.

It is well-known that an 21 old individual, at his acme of maturenesses, presents the following percentages of water in his skin layers [5-7]:

$70 \%$ in the stratum basale

$60 \%$ in the stratum granulosum and malpighianum

$30-40 \%$ in the stratum lucidum

$20 \%$ in the stratum corneum

$10 \%$ in the squamous superficial layer.

Physiologically speaking the amount of extracellular water tends to decrease progressively and constantly till the extreme old age and the same percentages of water are then retrieved in cadaver. These values are to be considered legitimate when this individual is supposed to live in a "ideal and theoretical environmental milieu" where temperature is for most of the time at $23^{\circ} \mathrm{C}$ (air temperature) and relative humidity is $35 \%$, so that TEWL is relatively contained $\left(7.5-10.2 \mathrm{~g} / \mathrm{m}^{2} \mathrm{~h}\right)$ and when every leap of temperature and humidity or excessive sun exposure (for job or mere aesthetical reasons) are classified as accidental exceptions, so that the just time can be accorded to recovery the standard physiological requirements to guarantee safety and integrity to skin.

TEWL seems to follow odd stratagems, actually, when, for instance, at $23^{\circ} \mathrm{C}$ and at relative humidity of $57 \%$ rises to $12.2 \mathrm{~g} /$ $\mathrm{m}^{2} \mathrm{~h}$, but, indeed, at r.h. of $88 \%$ decreases to $4.1 \mathrm{~g} / \mathrm{m}^{2} \mathrm{~h}$.

For, high relative humidity appears to represent the touche-sane to yield the decrease of TEWL, and this is undeniable when temperatures are contained and constant.

Environmental pollution, as well extreme changes of temperatures, we have already stated, embody one of the causes of excessive secretion of cortisol, that, dermatologically speaking, it is known to be responsible of the inhibition of the regeneration of the stratum granulosum (which is to be considered the water reservoir par excellence), of the synthesis of melatonin and of the proliferation of collagen and other active mesenchymal elements and of the immune counterattack to external assaults.

Xanthines and cocaine are generally reputed the responsible of cortisol release both endogenously and exogenously.

Conner et. al [8] referred that adhesive patches containing $300 \mathrm{mg}$ caffeine dispersed in a 5\% agarose and 5\% activated carbon hydrophilic gel, applied on the chest of twenty volunteers, permitted the plasmatic collection of caffeine transdermally adsorbed (more than 150ng after 3 hours) and it is not erratic to simulate the neurological stress onto skin employing natural xanthines for external use, in order to evaluate its influence on the cortisol release that can lead to the accelerated skin ageing. Aims of our research is to evaluate how a simulation of a "phytoinduced" increase of secretion of cortisol may induce praecox human skin senescence.

\section{Material and Methods}

We have decided to select to conduct our study particular individuals that may choose to live at physical environmental conditions that can guarantee the conservation of intact skin physiology or may not.

For, we have recruited 20 nuns in a cloistered convent in Mid Italy, located very close to a big polluted town, even if in the countryside: ten of these are accustomed to live and have always lived inside the cloister since the very tenderest age, and their life-style permits the good conservation of the intact skin physiology (that is living at air temperature and medium-low relative humidity so that two of the nuns of this group which are centennial, are characterised by matte, soft and soft skin without any apparent wrinkle) and the other ten are accustomed to live and work outdoor and in contact with the environmental assault of chemical and physical assaults.

Plans of our study were dispatched to the competence of the department of Work, Health and Social Politics at Rome. An informed consent was obtained from each volunteer prior to participate to the experiment.

We have prepared a cosmetic hydrogel made up of $2 \%$ hydroxypropylguar, containing a 5\% mix of herbal extracts containing $0.5 \%$ of titrated pure xanthines (Davilla rugosa folium, Maytenius macrocarpa folium and Sterculia platanifolia folium). The extracts of these three plants are admitted by INCI, COLIPA and CTFA rules.

So we extracted all the collected leaves in ethanol in order to prepare the $5 \%$ herbal-hydrogel and to begin the experiments at half March and conclude these at half October (29 weeks of treatment or simulation of the aggression by effects of global warming).

All the 20 volunteers were gently requested to spread every morning and every afternoon, at the same time, the gel onto the left ventral forearm for all the 29 weeks, to simulate the phytoinduced cortisol release.

At the beginning of the experiment we had previously measured the electrical admittance magnitude (in $\mu$ mho) using an appropriate instrument based on the system developed by Feldman [9] working at a single frequency of $30 \mathrm{kHz}$. This special excitation frequency was generated using a $4 \mathrm{Khz}$ crystal with digital counter chip. The counter output was converted into a sinusoidal current signal which was applied to two outer electrodes, meanwhile the instantaneous voltage signal between the inner signal was amplified by appropriate amplifier [9-12]. All the aforesaid tools and the amplifier were furnished by BioLogic Science Instruments, France.

We distinguished with precise accuracy the two groups of indoor (1001-1010) and the outdoor nuns (2001-2010) and we have been able to fill out Table I, as far as the values measured at the very beginning of the warm season, and afterwards, Table II, as far as the final values measured after 29 weeks of treatment with the xanthines-hydrogel, that is the simulation of the phytoinduces praecox senescence of skin.

\section{Results and Discussion}

After 29 weeks, simple observational analysis and analysis by magnifying glass of the treated skin (with the xanthineshydrogel) of the 20 volunteers revealed that skin rubor was evident only in all the volunteers of the second group, except for 2003 and 2008 that are dark and olive skinned (Malagasy and Nigerian). 
Here follow the Tables I and II, that should exhaustively, through their comparison, disclose the complete comprehension of the phenomenon we decided to study and clarify that the hypothesis mentioned in the introduction of our study is true and therefore conclusions can be derived.

Suggestive are the values of the electrical admittance magnitude with regard to the age of the volunteers, and this demonstrates the irreducible fact that the higher is the hydration (regarded

\begin{tabular}{|cc|c|}
\hline $\begin{array}{c}\text { Volunteer and her } \\
\text { age }\end{array}$ & $\begin{array}{c}\boldsymbol{\mu} \text { Mho at the beginning of } \\
\text { the experiment (at 30kHz). } \\
\text { March, 14th }\end{array}$ \\
\hline 1001 & 44 & 2710 \\
\hline 1002 & 27 & 1790 \\
\hline 1003 & 31 & 1980 \\
\hline 1004 & 59 & 2650 \\
\hline 1005 & 55 & 2590 \\
\hline 1006 & 47 & 2610 \\
\hline 1007 & 19 & 990 \\
\hline 1008 & 22 & 1880 \\
\hline 1009 & 68 & 2840 \\
\hline 1010 & 51 & 2600 \\
\hline 2001 & 31 & 1140 \\
\hline 2002 & 24 & 1250 \\
\hline 2003 & 27 & 1460 \\
\hline 2004 & 32 & 1440 \\
\hline 2005 & 30 & 1030 \\
\hline 2006 & 28 & 1250 \\
\hline 2007 & 36 & 1610 \\
\hline 2008 & 21 & 1220 \\
\hline 2009 & 30 & 1470 \\
\hline 2010 & 24 & 1350 \\
\hline & & 5 \\
\hline
\end{tabular}

Table I. Values of the electric admittance amplitude at the beginning of the experiment.

In the case of the volunteers of the first group (the indoor nuns), the influence of the sole simulation of the phyto-induced cortisol release appears to be lower than in the case of the volunteers of the second group (the outdoor nuns) where the influence of the xanthine-hydrogel that induced cortisol release is macroscopic. Values of the volunteers of the first group are evident in Table III, while values of the volunteers of the second group are plotted in Table IV.

All values are recorded as percentage of absolute dehydration.

\section{Conclusion}

It is undeniable that biological stress (by mean of exposition to changes of environmental temperature and pollutants, by mean of a simulation evoked by the use of a xanthine-hydrogel) does represent a very liaison dangereuse for the integrity and wellness of human skin. as water content and water permeability through the layers of derma), the lower is the value of the electrical admittance magnitude, and vice versa, the lower is the hydration, the higher will be the electrical admittance magnitude.

The Hydration degree (and par consequence the coefficient of Skin Moisture) is irrefutably due to age and distantness from excessive changes of temperature and pollutants aggression.

\begin{tabular}{|cc|c|}
\hline $\begin{array}{c}\text { Volunteer and her } \\
\text { age }\end{array}$ & $\begin{array}{c}\text { AMho at the end of the } \\
\text { experiment (at 30kHz). } \\
\text { October, 16th }\end{array}$ \\
\hline 1001 & 44 & 3330 \\
\hline 1002 & 27 & 2020 \\
\hline 1003 & 31 & 2070 \\
\hline 1004 & 59 & 3040 \\
\hline 1005 & 55 & 3060 \\
\hline 1006 & 47 & 3170 \\
\hline 1007 & 19 & 1890 \\
\hline 1008 & 22 & 2470 \\
\hline 1009 & 68 & 3110 \\
\hline 1010 & 51 & 3440 \\
\hline 2001 & 31 & 2600 \\
\hline 2002 & 24 & 2470 \\
\hline 2003 & 27 & 1860 \\
\hline 2004 & 32 & 2910 \\
\hline 2005 & 30 & 2740 \\
\hline 2006 & 28 & 1980 \\
\hline 2007 & 36 & 3000 \\
\hline 2008 & 21 & 1560 \\
\hline 2009 & 30 & 1990 \\
\hline 2010 & 24 & 2210 \\
\hline & & \\
\hline
\end{tabular}

Table II. Values of the electric admittance amplitude at the end of the experiment.

It is suggestive the fact that we have expressly selected these peculiar types of subjects (the cloistered nuns) because they are able to show the devastative degradation evoked by climate changes and pollutants onto skin in dependence of their own choice they can do to live outdoor or indoor.

The must impressive results come out from the values of the electrical admittance magnitude recorded in all the volunteers of the second group, where the simulated phyto-induced stress reveals an huge increase of the absolute dehydration after 29 weeks.

It is noticeable that even in the volunteers of the first group (the indoor nuns), the values of the electrical admittance magnitude are relatively higher, notwithstanding the volunteers have the chance not to be assaulted by abrupt changes of climate and temperature and pollutants, as well. 


\begin{tabular}{|c|c|}
\hline $\begin{array}{c}\text { Volunteer and her } \\
\text { age }\end{array}$ & $\begin{array}{c}\text { Absolute dehydration after 29 } \\
\text { weeks }\end{array}$ \\
\hline 1001 & $18.62 \%$ \\
\hline 1002 & $11.39 \%$ \\
\hline 1003 & $4.40 \%$ \\
\hline 1004 & $12.90 \%$ \\
\hline 1005 & $15.40 \%$ \\
\hline 1006 & $17.70 \%$ \\
\hline 1007 & $47.62 \%$ \\
\hline 1008 & $23.89 \%$ \\
\hline 1009 & $8.62 \%$ \\
\hline 1010 & $24.42 \%$ \\
\hline
\end{tabular}

Table III. Values of skin dehydration recorded after 29 weeks in the indoor volunteers.

\begin{tabular}{|c|c|}
\hline $\begin{array}{c}\text { Volunteer and her } \\
\text { age }\end{array}$ & $\begin{array}{c}\text { Absolute dehydration after 29 } \\
\text { weeks }\end{array}$ \\
\hline 2001 & $56.20 \%$ \\
\hline 2002 & $49.40 \%$ \\
\hline 2003 & $21-51 \%$ \\
\hline 2004 & $50.52 \%$ \\
\hline 2005 & $62.50 \%$ \\
\hline 2006 & $36.87 \%$ \\
\hline 2007 & $46.40 \%$ \\
\hline 2008 & $21.80 \%$ \\
\hline 2009 & $26.14 \%$ \\
\hline 2010 & $39.00 \%$ \\
\hline
\end{tabular}

Table IV. Values of skin dehydration recorded after 29 weeks in the outdoor volunteers.

\section{Acknowledgement}

We really can boast not to have received absolutely any funding or reimbursement by any authority or governmental corporation to conduct this study.

\section{REFERENCES}

1. Seyle Jhb. The Stress of Life.2nd ed.New York; Mc Graw-Hill;1978 2. Seyle JHB. Stress without distress.1st ed.Philadelphia; Lippincott Williams \& Wilkins; 1974

3. Berk LS, Tan SA, Berk D. Cortisol and Catecholamine stress hormone decrease is associated with the behavior of perceptual anticipation of mirthful laughter. FASEB J. 2008;22:946.11.

4. de Weerth C, Zijl RH, Buitelaar JK. Development of cortisol circadian rhythm in infancy. Early Hum Dev. 2003;73:39-52.

5. Jessen C. Temperature regulation in humans and other mammals. Berlin. Springer; 2000.

6. Fluhr J, Berardesca E, Elsner P, Maibach HI. Bioengineering of the skin: water and stratum corneum.2nd ed.Oxford (UK): CRC Press; 2004.
7. Gioia F, Celleno L. The dynamics of TEWL from hydrated skin. Skin Res Technol. 2002:8:178-86.

8. Conner DP, Millora E, Zamani K, Nix D, Almirez RG, RhyneKirsch P, Peck C. Transutaneous Chemical Collection of Caffeine in Normal Subjects. Relationship to Area Under the Plasma Concentration-Time Curve and Sweat Production. Proceedings of the 52th Annual Meeting of The Society for Investigative Dermatology. J Invest Dermatol. 1991;96:532-632.

9. Johnsen GK. Skin electrical properties and physical aspects of hydration of keratinized tissues. Thesis submitted for the degree of Philosophiae Doctor, Department of Physics, University of Oslo, June 2010.

10. Martinsen $\varnothing \mathrm{G}$, Grimnes S, Haug E. Measuring depth depends on frequency in electrical skin impedance measurements. Skin Res Technol. 1999;5:179-81.

11. Johnsen GK, Martinsen Ø.G, Grimnes S. Estimation of In Vivo Water Content of the Stratum Corneum from Electrical Measurements. Open Biomed Eng J. 2009;3:8-12.

12. Salter DC, Elsner P, Barel AO, Berardesca E, Gabard B, Serup J. Examination of Stratum corneum Hydration State by Electrical Methods. Skin Bioengineering Techniques and Applications in Dermatology and Cosmetology. Curr Probl Dermatol. 1998;26:3847. 